\title{
Wellens syndrome
}

\author{
Debraj Das MD, Nawaf S. Almajed MBBS MSc
}

See also pages 485, 528, www.cmaj.ca/lookup/doi/10.1503/cmaj.151209 and www.cmaj.ca/lookup/doi/10.1503/cmaj.150816

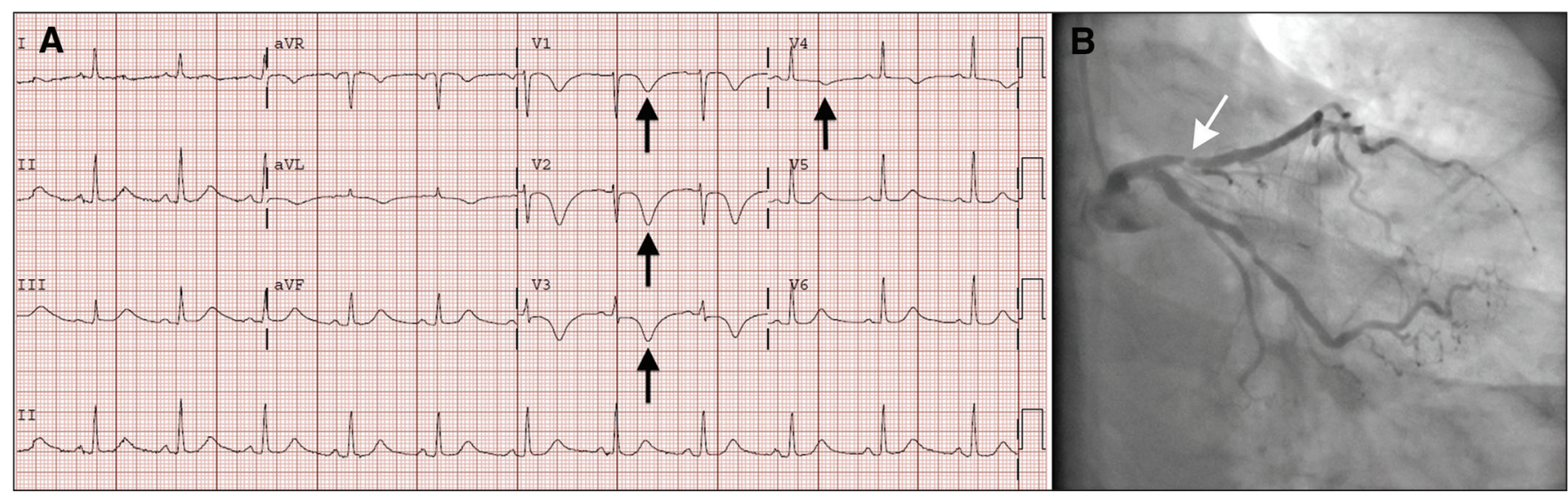

Figure 1: (A) Electrocardiogram showing the Wellens pattern (black arrows) in the precordial leads of a 70-year-old woman who presented to the emergency department with intermittent pain in the left arm over the preceding 24 hours. (B) Coronary angiogram showing $90 \%$ stenosis of the proximal left anterior descending artery (white arrow).

$\mathrm{A}$ 70-year-old woman presented with a 24-hour history of intermittent left arm pain. She had hypertension and a family history of premature coronary artery disease. Electrocardiography (ECG; Figure 1A) showed deep symmetric T-wave inversions in leads V1 to V4 and elevated troponin I level $(0.82 \mu \mathrm{g} / \mathrm{L})$. She was treated according to contemporary guidelines for non-ST segment elevation myocardial infarction. The risk of death or recurrent ischemic event was 19.9\% (TIMI [Thrombolysis in Myocardial Infarction] ${ }^{1}$ score of 4). Urgent coronary angiography showed $90 \%$ stenosis of the proximal left anterior descending coronary artery (Figure 1B), which was successfully revascularized with a single drug-eluting stent. The history and initial ECG and angiographic findings were in keeping with Wellens syndrome. Transthoracic echocardiography 24 hours later showed a normal left ventricle ejection fraction. Dual antiplatelet therapy for one year was prescribed, along with cardiac rehabilitation.

In the first report of Wellens syndrome, de Zwaan and colleagues ${ }^{2}$ described a subgroup of patients with unstable angina who were at high risk of extensive acute myocardial infarction of the anterior wall. These patients had distinctive ECG findings, including deep symmetric T-wave inversion or biphasic $\mathrm{T}$ waves in the anterior precordial leads, ST-segment changes (elevation or depression), absence of $\mathrm{Q}$ waves and normal R-wave progression. The characteristic $\mathrm{T}$-wave changes have $69 \%$ sensitivity, $89 \%$ specificity and $86 \%$ positive predictive value for clinically significant disease of the left anterior descending artery evident on coronary angiography. ${ }^{3}$ Although the pathophysiology is unknown, edema from the ischemic myocardial cell injury may result in the characteristic T-wave changes. ${ }^{4}$ These ECG findings are commonly seen in patients who have had recent ischemic chest pain but who may be pain-free at the time of presentation. Recognition of this ominous pattern is crucial for early diagnosis and intervention. ${ }^{5}$

\section{References}

1. Antman EM, Cohen M, Bernink PJLM, et al. The TIMI risk score for unstable angina/non-ST elevation MI: a method for prognostication and therapeutic decision making. JAMA 2000;284:835-42.

2. de Zwaan C, Bar FW, Wellens HJ. Characteristic electrocardiographic pattern indicating critical stenosis high in left anterior descending coronary artery in patients admitted because of impending myocardial infarction. Am Heart J 1982;103:730-6.

3. Haines DE, Raabe DS, Gundel WD, et al. Anatomic and prognostic significance of new $\mathrm{T}$-wave inversion in unstable angina. Am J Cardiol 1983;52:14-8.

4. Migliore F, Zorzi A, Marra MP, et al. Myocardial edema underlies dynamic T-wave inversion (Wellens' ECG pattern) in patients with reversible left ventricular dysfunction. Heart Rhythm 2011;8:1629-34.

5. Rhinehardt J, Brady WJ, Perron AD, et al. Electrocardiographic manifestations of Wellens' syndrome. Am J Emerg Med 2002;20:638-43.
Competing interests: None declared.

This article has been peer reviewed.

The authors have obtained patient consent.

Affiliations: Department of Medicine, Faculty of Medicine and Dentistry (Das), and Division of Cardiology, Mazankowski Alberta Heart Institute (Almajed), University of Alberta, Edmonton, Alta.

Correspondence to: Debraj Das, debraj.das@ualberta.ca

CMAJ 2016. DOI:10.1503 /cmaj.150550 